\title{
Inducible Overexpression of a Rice Allene Oxide Synthase Gene Increases the Endogenous Jasmonic Acid Level, $P R$ Gene Expression, and Host Resistance to Fungal Infection
}

\author{
Chuansheng Mei, ${ }^{1}$ Min Qi, ${ }^{1}$ Guangyao Sheng, ${ }^{2}$ and Yinong Yang ${ }^{1}$ \\ ${ }^{1}$ Department of Plant Pathology and Program in Cell and Molecular Biology, and ${ }^{2}$ Department of Crop, Soil, and \\ Environmental Sciences, University of Arkansas, Fayetteville 72071, U.S.A.
}

Submitted 12 February 2006. Accepted 21 June 2006.

\begin{abstract}
Many studies in dicotyledonous plants have shown that jasmonates, including jasmonic acid (JA) and methyl jasmonate, are important signal molecules involved in induced resistance to pathogen infection and insect herbivory. However, very little genetic and molecular evidence is available to demonstrate their role in host defense response of rice and other economically important monocot plants. In this study, we have shown that exogenous application of JA was able to activate defense gene expression and local induced resistance in rice seedlings against the rice blast fungus (Magnaporthe grisea). Furthermore, we have characterized a pathogen-inducible rice $O S A O S 2$ gene (which encodes allene oxide synthase, a key enzyme in the JA biosynthetic pathway) and examined the role of endogenous $\mathrm{JA}$ in rice defense response through transgenic manipulation of the JA biosynthesis. Sequence analysis indicated that OsAOS2 contains four common domains of the cytochrome P450 enzyme, but does not have the signal peptide for chloroplast targeting. The basal level of OsAOS2 expression is very low in leaves but relatively high in the sheath, culm, and flower of rice plants. Interestingly, the expression of $O s A O S 2$ in rice leaves can be induced significantly upon $M$. grisea infection. Transgenic rice lines carrying the OsAOS2 transgene under the control of a strong, pathogen-inducible $P B Z 1$ promoter accumulated abundant $O S A O S 2$ transcripts and higher levels of JA, especially after the pathogen infection. These transgenic lines also exhibited enhanced activation of pathogenesis-related $(P R)$ genes such as $P R 1 a, P R 3$, and $P R 5$ and increased resistance to $M$. grisea infection. Our results suggest that $\mathrm{JA}$ plays a significant role in $P R$ gene induction and blast resistance in rice plants.
\end{abstract}

Additional keywords: Oryza sativa

Corresponding author: Y. Yang; Telephone: +1.479.575.5635; Fax: +1.479.575.7601; E-mail: yiyang@uark.edu

Current address of Chuansheng Mei: Department of Crop and Soil Sciences, Michigan State University, East Lansing 48824, U.S.A.

Current address of Min Qi: E402/4239, DuPont Central Research and Development, PO Box 80402, Wilmington, DE 19880, U.S.A.

Nucleotide sequence data for OsAOS2 is available in the GenBank database under accession number AY310358.
Jasmonates are lipid-derived regulators that mediate biotic and abiotic stress responses as well as plant growth, development, and senescence (Creelman and Mullet 1997; He et al. 2002; Howe and Schilmiller 2002; Turner et al. 2002; Weber 2002). A large body of genetic and molecular evidence has shown that jasmonates are key endogenous signals involved in plant defense response to pathogen infection and insect herbivory (Farmer et al. 2003, Kessler et al. 2004). For example, Arabidopsis mutants impaired in jasmonic acid (JA) perception (e.g., coil, jarl, and jinl) or biosynthesis (e.g., aos, fad3/7/8, opr3/dde1, and dad1) are unable to deploy effective defense responses against pathogen infection (Feys et al. 1994; Park et al. 2002; Penninckx et al. 1996; Sanders et al. 2000; Stintzi and Browse 2000; Thomma et al. 1998; Turner et al. 2002; Vijayan et al. 1998; Xie et al. 1998). By contrast, Arabidopsis mutants (e.g., cevl) with constitutive activation of the JA pathway exhibit enhanced resistance to bacterial and fungal pathogens (Ellis et al. 2002; Ellis and Turner 2001). In addition to Arabidopsis, the importance of jasmonates in defense gene expression and disease resistance also has been demonstrated in tomato, tobacco, and potato plants through mutant or transgenic plant analysis (Cohen et al. 1993; Harms et al. 1995; Howe et al. 2000; Howe and Ryan 1999; Laudert et al. 2000; Li et al. 2001; Sivasanker et al. 2000; Wang et al. 1999).

Although the role of JA in disease resistance has been well established in dicotyledonous plants, little is known about its function in host defense response of rice and other economically important monocot plants. To date, most of the information comes from the studies of exogenous JA or methyl jasmonate (MeJA) treatments on the induction of rice defense genes or phytoalexins. Exogenous JA treatment was shown to induce a number of pathogenesis-related $(P R)$ genes in rice, including PRla (Agrawal et al. 2000a), PRIb (Agrawal et al. 2000b), PR2 (Simmons et al. 1992), PR3 (Xu et al. 1996), PR5 (Rakwal and Komatsu 2000), and PRIO (Jwa et al. 2001). JA also induces many other stress or defense-related rice genes (Lee et al. 2001; Moons et al. 1997; Rakwal and Komatsu 2000; Sasaki et al. 2001; Xiong et al. 2001). In addition, exogenous application of JA was reported to increase the production of phytoalexins sakuranetin and momilactone A in rice leaves (Nojiri et al. 1996; Tamogami et al. 1997). Reduction of endogenous JA levels with tetcyclacis, an inhibitor of jasmonate biosynthesis, significantly inhibits the pathogen-induced PR1 accumulation (Schweizer et al. 1997a). These results indirectly demonstrate that JA may play an important role in defense 
gene activation and disease resistance responses in rice plants. However, Schweizer and associates (1997b) showed that inoculation of rice seedlings with Magnaporthe grisea or Pseudomonas syringae pv. syringae (a nonpathogen) did not significantly increase the endogenous levels of JA despite the induction of $P R$ genes. Paradoxically, exogenous JA application or wounding (which induces transient accumulation of JA) only led to induced blast resistance in systemic leaves but not in local, treated leaves (Schewizer et al. 1998). Therefore, the role of JA in rice defense response is not clear and needs to be further elucidated through more robust genetic and molecular analysis using rice mutants or transgenic lines with altered JA production or signal perception.

The jasmonate biosynthetic pathway, which begins with fatty acid linolinic acid, has been fairly well characterized in plants (Liechti and Farmer 2003; Turner et al. 2002). Allene oxide synthase (AOS, EC 4.2.1.92, hydroperoxide dehydratase) is a key enzyme in the pathway and catalyzes the dehydration of 13-hydroperoxy octadecatrienoic acid to an unstable epoxide, which then is converted by allene oxide cyclase to the cyclopentenone ring-containing 12-oxo-phytodienoic acid (OPDA), the direct precursor of JA. AOS first was identified as a cytochrome P450 enzyme from flax (Song and Brash 1991) and subsequently was cloned and characterized in flax (Linum usitatissimum; Song et al. 1993), gueyule (Pathenium argentatum; Pan et al. 1995), Arabidopsis (Laudert et al. 1996), tobacco (Nicotiana attenuate; Ziegler et al. 2001), tomato (Lycopersicon esculentum; Howe et al. 2000; Sivasankar et al. 2000), barley (Hordeum vulgare; Maucher et al. 2000), and rice (Oryza sativa; Agrawal et al. 2002; Ha et al. 2002; Haga and Iino 2004). In Arabidopsis, the expression of AOS is activated by wounding, jasmonate, and salicylate and occurs in anthers and pollens (Kubigsteltig et al. 1999; Laudert and Weiler 1998). However, overexpression of Arabidopsis AOS using constitutive CaMV $35 S$ promoter did not alter the basal level of JA in transgenic Arabidopsis and tobacco (Laudert et al. 2000). However, when the transgenic plants were wounded, they produced two- to threefold higher levels of JA than did wounded control plants. In contrast, overexpression of flax $A O S$ in transgenic potato led to a 6- to 12-fold higher level of endogenous JA than nontransgenic plants (Harms et al. 1995). Recently, Arabidopsis AOS mutants have been obtained through transposon or T-DNA insertional mutagenesis (Park et al. 2002; von Malek et al. 2002). These mutants are defective in JA biosynthesis and exhibit male sterility that can be rescued by exogenous application of MeJA, confirming that $A O S$ is essential for the biosynthesis of biologically active jasmonates.

In contrast to Arabidopsis, which carries a single $A O S$ gene, the rice genome appears to contain four AOS genes (Agrawal et al. 2004; Haga and Iino 2004). Although some rice AOS $(O s A O S)$ genes have been isolated and analyzed for their mRNA expression patterns during the course of our study (Agrawal et al. 2002; Ha et al. 2002; Haga and Iino 2004), transgenic analysis and functional characterization of $A O S$ have not been reported in rice or any other monocotyledonous plants. In this study, we first examined the effect of exogenous JA treatment on the basic $P R 1$ gene $(P R I b)$ expression and induced resistance against $M$. grisea infection. We then identified a pathogeninducible rice $A O S$ gene (OSAOS2). Furthermore, transgenic rice lines were generated, which carried the OsAOS 2 transgene under the control of a strong, pathogen-inducible promoter of rice PBZ1 gene (which encodes an intracellular PR10 protein) (Midoh and Iwata 1996). Molecular, biochemical, and pathological analyses of the first (T0), second (T1), and third (T2) generations of transgenic rice lines revealed that $O s A O S 2$ plays a significant role in pathogen-induced JA biosynthesis, defense gene activation, and host resistance to the rice blast fungus.

\section{RESULTS}

Activation of rice $P R I b$ gene and induced resistance by exogenous JA treatment.

To examine the effect of exogenous JA on induced resistance, 2-week-old rice seedlings were treated with JA, along with Salicylic acid (SA), benzothiadiazole (BTH, a synthetic activator of induced resistance in many plants), or probenazole (PBZ, a fungicide and activator of induced resistance in rice). To verify the effectiveness of chemical sprays, the rice $P R I b$ expression was monitored at $0,1,2$, and 3 days after the treatments. RNA blot analysis showed that rice $P R 1 b$ gene was induced only weakly, if at all, by SA, but was strongly activated by JA (Fig. 1A). In addition, $P R 1 b$ also was induced significantly in BTHor PBZ-treated leaves. However, induction of $P R 1 b$ was not detected in upper, systemic leaves (data not shown).

Three days after chemical treatments, rice seedlings were inoculated with $M$. grisea. Induced resistance against $M$. grisea infection was evaluated at 6 days postinoculation. The pretreatment with SA, a poor inducer of basic $P R 1$ genes, failed to activate induced resistance against blast infection (Fig. 1B). In contrast, pretreatments with JA, BTH, and PBZ, which are effective inducers of the $P R 1 b$ gene, conferred significant levels of induced resistance, as shown by reduced lesion size and number in pretreated leaves. Compared with the $\mathrm{H}_{2} \mathrm{O}$ control, pretreatments with JA, BTH, and PBZ resulted in 65, 66, and $47 \%$ reduction in lesion number and 51,47 , and $43 \%$ reduction in lesion size, respectively. In addition to visual assessment of disease severity, the growth of $M$. grisea in rice seedlings was quantified by the real-time polymerase chain reaction (PCR) using a specific pair of primers designed according to the $3^{\prime}$ untranslated region of 28S rDNA of $M$. grisea (Qi and Yang 2002). The pretreatment of rice seedlings with JA, BTH, and PBZ resulted in 84,80 , and $66 \%$ reduction of the fungal growth, respectively. These data demonstrate that JA is an effective activator of induced resistance as well as basic PRI expression in rice plants.

\section{Sequence analysis of $O$ sAOS 2 cDNA.}

The OsAOS 2 gene is 1,775 bp long, including the 1,437-bp open reading frame region encoding a $52.3-\mathrm{kDa}$ protein with 478 amino acids and a theoretical pI of 8.21. The result from sequence alignment indicated that OsAOS2 has four conserved domains of cytochrome P450 proteins (Fig. 2A, domains AD), which are common for all AOS enzymes. Similarly to the AOSs from barley and wheat, OsAOS2 lacks an amino-terminal transit peptide for targeting to the chloroplast, which is different from many AOSs of dicotyledonous species such as Arabidopsis, tomato, tobacco, and flax. The gene we reported here is the same as the OSAOS gene reported by Agrawal and associates (2002) and $\mathrm{Ha}$ and associates (2002), and the OsAOS2 gene reported by Haga and Iino (2004). Southern blot analysis revealed a single, strong hybridizing band in the EcoRI or HindIII digestion after probing with the full-length OsAOS 2 cDNA (Fig. 2B), indicating that OsAOS2 is a singlecopy gene. The weakly hybridizing bands suggest the presence of other related genes. It was reported recently that the rice genome contains four members of the small $A O S$ gene family (Agrawal et al. 2004; Haga and Iino 2004).

The AOS phylogenetic analysis showed that OsAOS2 was very closely related to those from other monocotyledonous species, such as barley and wheat (Fig. 2C). OsAOS2 was $73.5,72.6$, and $69.9 \%$ identical at the amino acid sequence level with barley AOS1, barley AOS2, and wheat AOS, respectively, but only 50.6, 49.6, 48.1, 48.0, 47.8, 45.9, 45.6, 45.5, and $43.6 \%$ identical with the AOS proteins from guayule, potato, tobacco, Arabidopsis, tomato, Medicago truncatula, flax, 
muskmelon, and Physcomitrella patens, respectively. OsAOS2 shared $55 \%$ sequence identity with OsAOS1, the only AOS enzyme identified so far to contain a chloroplast transit peptide in monocotyledonous species (Haga and Iino 2004).

\section{Tissue-specific expression of $O s A O S 2$.}

In rice plants, the expression level of $O s A O S 2$ is very low and hardly detectable by RNA gel blot analysis. Therefore, real-time reverse-transcription (RT)-PCR was used to determine the expression pattern of OsAOS2. The total RNA was extracted from 2-week-old and 2-month-old leaves, sheath, and roots at vegetative stages and from culm, young panicle, panicle, and florets at reproductive stage. The expression analysis revealed the highest level of OSAOS2 expression in the 2week-old sheath, which was 90-fold higher than the lowest expression of OSAOS2 in the 2-week-old leaf (Fig. 3). Culm and panicle also had relatively high levels of OsAOS2 expression.

\section{Induction of $\mathrm{OsAOS} 2$ during Magnaporthe grisea infection.}

In order to examine the expression of OsAOS2 in response to pathogen infection, 2-week-old rice seedlings were sprayinoculated with the blast fungus. Leaf samples were taken daily from day 0 to day 4 for RNA isolation and subsequent quantitative RT-PCR assays. Upon Magnaporthe grisea infection, the level of OSAOS 2 expression was induced dramatically at day 1 and reached the highest level at day 2, when small blast lesions started to appear on the infected leaves (Fig. 4). The expression of OsAOS 2 slightly decreased but remained high at 3 and 4 days post infection. In the mock-inoculated leaves, the OsAOS2 expression increased only at day 1 and then went back to the basal level. The transient increase of OsAOS 2 expression in the mock treatment at day 1 likely was due to general stress effect in the dew chamber. In contrast to the OsAOS 2 induction by $M$. grisea infection, wounding or defense signal molecules such as JA, SA, abscisic acid, BTH (a functional analog of SA), and ethephon (an ethylene releaser) did not significantly activate the expression of OsAOS 2 in rice leave (data not shown).

\section{Inducible overexpression of $\mathrm{OSAOS} 2$ transgene in rice.}

To further clarify the function of OsAOS2 in the JA biosynthesis pathway and determine the role of JA in $P R$ gene induction and defense response in rice, the full-length OsAOS2 cDNA was fused with the rice $P B Z 1$ gene promoter that is inducible strongly by pathogen infection. The PBZ1::OsAOS2 construct then was introduced into rice cv. Nipponbare via the Agrobacterium-mediated transformation. In all, 21 independent transgenic lines were generated and confirmed by Southern blot analysis. As indicated in the genomic Southern blot (Fig. 5A), all transgenic lines carried an additional 2.5-kb EcoRI fragment hybridizing with the OsAOS 2 cDNA probe, whereas the wild-type control plant contained only a $3.0-\mathrm{kb}$ hybridizing fragment. Furthermore, RNA blot showed a strongly induced expression of $O s A O S 2$ in the transgenic lines compared with a very low level of $O s A O S 2$ in the untransformed control plant (Fig. 5B). The pathogen-inducible $P B Z 1$ promoter (rather than a constitutive promoter) was used to control the expression of OsAOS 2 transgene; therefore, considerable variation was ob-
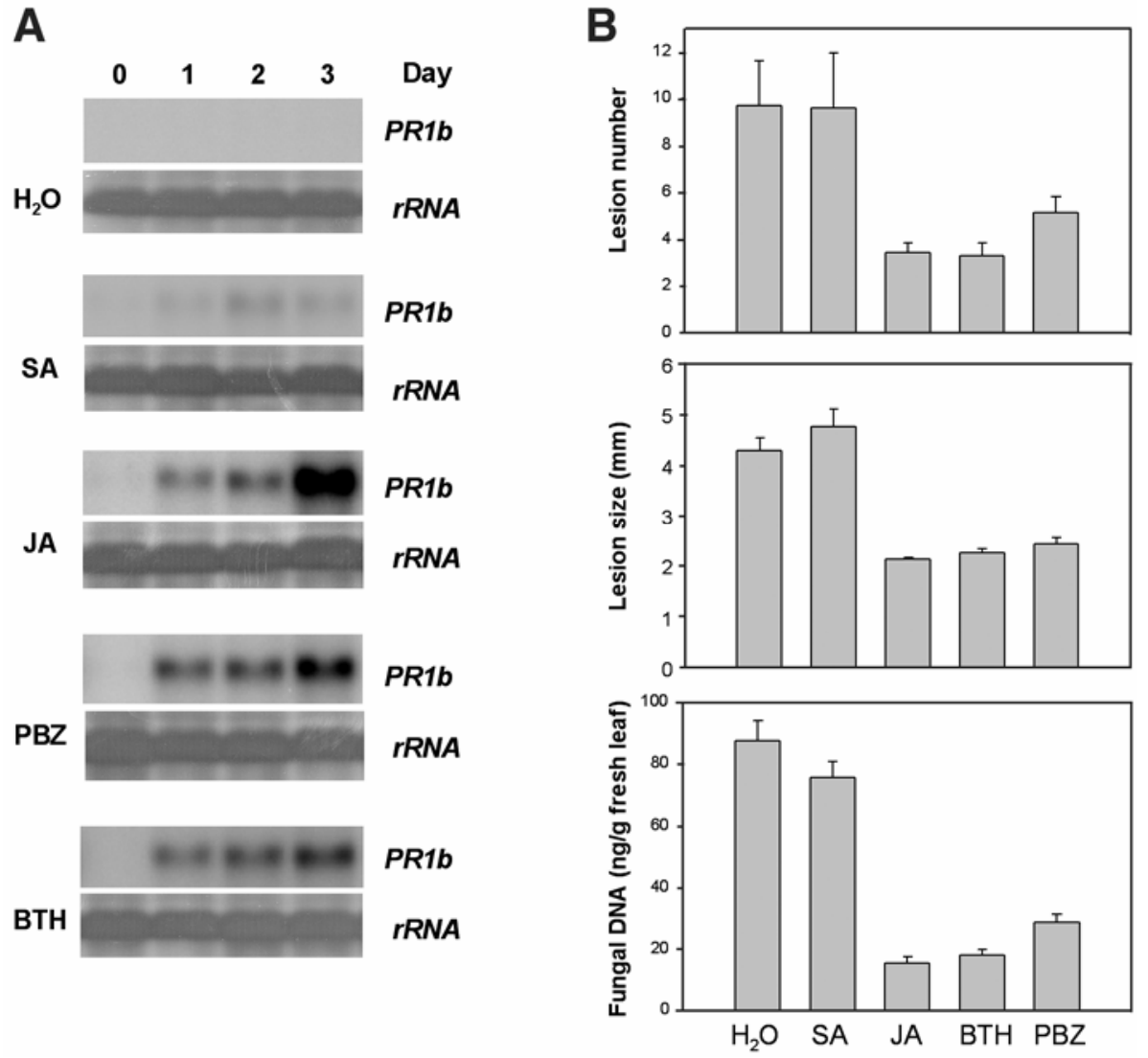

Fig. 1. Activation of $P R l b$ and induced resistance in chemical-treated rice seedlings. A, Expression of rice $P R 1 b$ gene in response to chemical treatments. Total RNAs were isolated from rice leaves sprayed with $\mathrm{H}_{2} \mathrm{O}$, salicylic acid (SA, $1.5 \mathrm{mM}$ ), jasmonic acid (JA, $0.1 \mathrm{mM}$ ), probenazole (PBZ, $0.25 \mathrm{mM}$ ), and benzothiadiazole (BTH, $0.25 \mathrm{mM}$ ) and probed with the rice $P R 1 b$ or $25 \mathrm{~S}$ rDNA fragment. B, Activation of local induced resistance against the infection of Magnaporthe grisea. At least 125 seedlings were scored and analyzed for each experiment. Statistical analysis $(t$ test) has shown a significant reduction $(<0.05)$ of lesion number, lesion size, and the fungal growth in JA-, PBZ- and BTH-treated leaves. The standard errors were indicated in the figure. Similar results were obtained in three experiments. 
served in the level of $O s A O S 2$ transcripts in individual transgenic plants following the $M$. grisea infection.

\section{Accumulation and pathogen-induced elevation of endogenous JA levels in OsAOS2 transgenic rice.}

To correlate the OsAOS2 overexpression with increased JA biosynthesis, gas chromatography mass spectrometry (GCMS) was used to determine JA levels in transgenic rice lines (see Materials and Methods). The mass spectra of endogenous JA from rice leaves matched very well with that of authentic JA standard, as indicated by the similar relative abundance of major ions between the JA standard and endogenous JA from rice leaf tissues (Fig. 6A). For JA quantification, an internal standard 9,10-dihydro jasmonic acid (DHJA, which was not detected in rice leaves under the same conditions) was included for adjusting the JA extraction efficiency. The area of $\mathrm{m} / \mathrm{z} 224$ of methyl JA and m/z 153 of methyl DHJA was used to calculate JA and DHJA amounts, respectively. The standard curve of area ratio of methyl JA and methyl DHJA versus amount ratio of JA and DHJA was plotted and showed a linear regression with $R^{2}=0.99$ (Fig. 6B).

Under normal growth conditions (in the absence of pathogen infection), the OsAOS2 overexpression lines had relatively higher basal levels of JA (12 to $21 \mathrm{ng} / \mathrm{g}$ of fresh weight [FW]) than that of the control plant (7.5 ng/g of FW) (Fig. 6C). Upon infection by $M$. grisea, a drastic increase of endogenous JA (51 to $282 \mathrm{ng} / \mathrm{g}$ of $\mathrm{FW}$ ) was observed in the transgenic lines carrying the pathogen-inducible PBZ1::OsAOS2 transgene (Fig. 6D). In contrast, only a modest increase of endogenous JA (36 $\mathrm{ng} / \mathrm{g}$ of $\mathrm{FW}$ ) was found in the $M$. grisea-infected control plant. Therefore, inducible overexpression of OsAOS2 indeed contributed to the increased level of endogenous JA in transgenic rice, especially in the presence of pathogen infection.

A

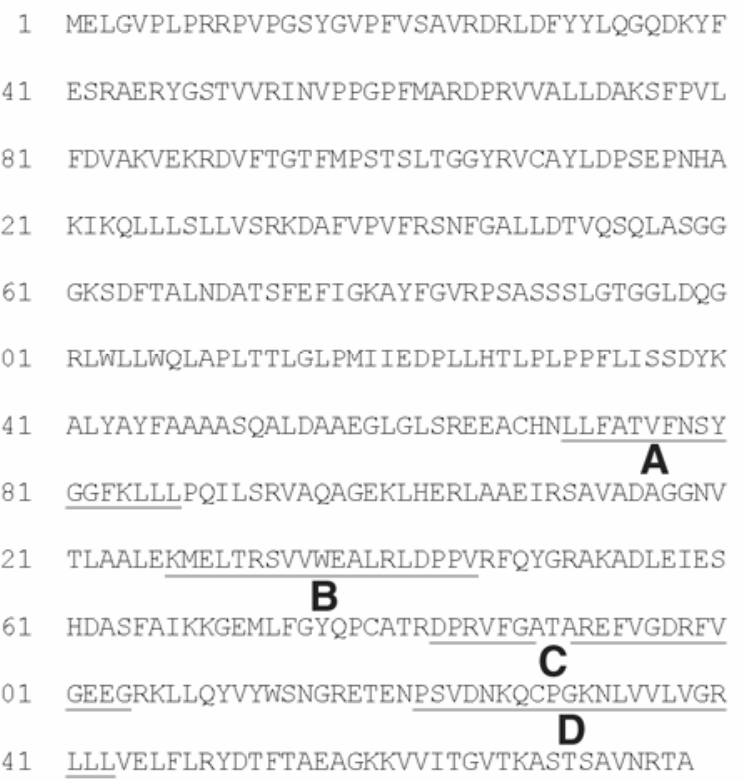

Enhanced activation of $P R$ genes in $O S A O S 2$ transgenic rice.

It has been well documented that exogenous application of $J A$ could induce the expression of various $P R$ genes in rice and other plants. To determine whether elevated levels of endogenous JA could activate rice $P R$ genes in the $O S A O S 2$ transgenic lines, the expression of six $P R$ genes was examined in the detached leaves of the control and transgenic plants. In general, the transgenic lines had a much higher level of $P R$ gene expression than that of the control plants (Fig. 7), especially for PRIa, $P R 3$, and $P R 5$. In the OX3 lines, for instance, the levels of PRIa, PR3, and PR5 expression were 554, 204, and 1,524 higher, respectively, than those in the untransformed control plant. The expression of $P R 1 b, P R 2$, and $P B Z 1$ genes also was higher in most of transgenic lines compared with that of the control plant. These data demonstrated that inducible overexpression of OSAOS2 transgene not only increased the level of endogenous JA but also significantly activated the expression of many $P R$ genes in transgenic rice lines.

\section{Increased resistance of $O s A O S 2$ transgenic lines to $M$. grisea infection.}

The inducible overexpression of OSAOS2 transgene was found to increase the levels of endogenous JA and $P R$ gene expression; therefore, the transgenic rice lines were evaluated further for disease resistance to the blast fungus. Following infection with a moderately virulent $M$. grisea isolate, the disease severity was significantly lower in the transgenic lines than that of the control plant (Fig. 8A). In addition, a 32 to $83 \%$ reduction in $M$. grisea growth was observed in the transgenic lines compared with the control plant (Fig. 8B), indicating a significant increase of disease resistance to $M$. grisea infection.
B

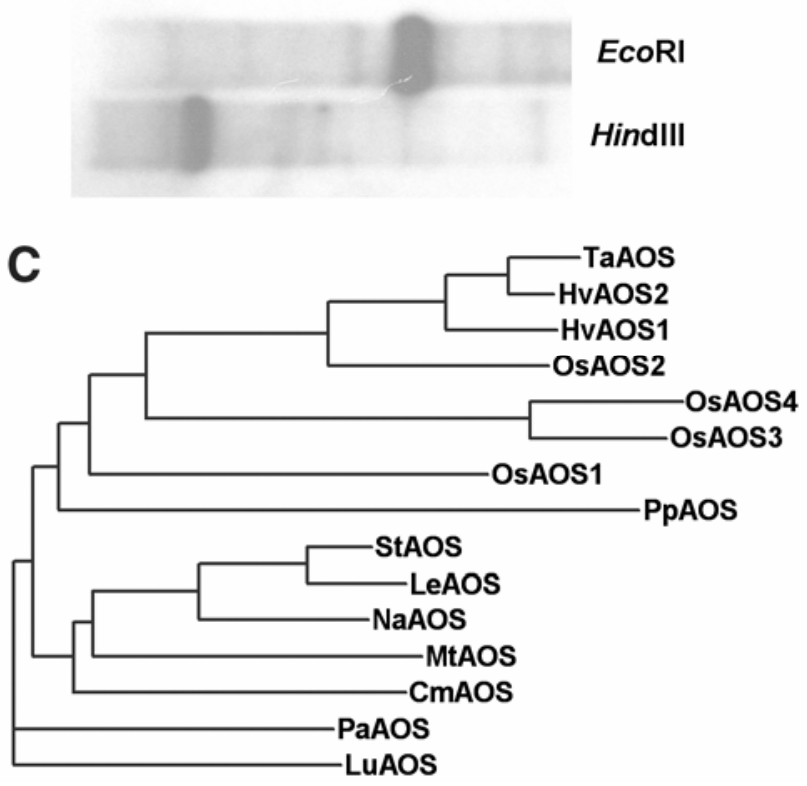

Fig. 2. Oryza sativa allene oxide synthase (OsAOS)2 and its relationship with other plant allene oxide synthase AOS proteins. A, Deduced amino acid sequence of OsAOS2 with four conserved domains (A to D) of cytochrome P450 in C-terminal region. B, Southern blot analysis of OsAOS2 in rice genome. Total DNA from rice cv. Nipponbare was digested individually with EcoRI and HindIII and hybridized with the full-length cDNA probe of $O s A O S 2$. C, Relationship between OsAOS2 and other plant AOS proteins. The dendrogram was generated based on the multiple sequence alignment of the following AOS proteins: AtAOS (Arabidopsis thaliana Y12636), CmAOS (muskmelon, Cucumis melo AAM66138), HvAOS1 and 2 (barley, Hordeum vulgare 1, AJ250864 and 2, AJ251304), LeAOS (tomato, Lycopersicon esculentum AF230371), LuAOS (flax, Linum usitatissimum U00428), MtAOS (Medicago truncatula AJ316561), NaAOS (tobacco, Nicotiana attenuata CAC82911), PaAOS (guayule, Pathenium argentatum X78166), PpAOS (moss, Physcomitrella patens AJ316566), OsAOS1-4 (rice, Oryza sativa, AY062258, AY310358, AK105964, and AK068620), StAOS (potato, Solanum tuberosum AAN37417), and TaAOS (wheat, Triticum aestivum AY196004). 


\section{DISCUSSION}

During the past decades, JA was found to play an important role in plant disease resistance in addition to its well-documented involvement in induced resistance against insect herbivory (Dong 1998; Farmer et al. 2003; Reymond and Farmer 1998). JA was suggested to mediate induced resistance through a distinct, SA-independent signaling pathway or interact with SA, ethylene, reactive oxygen intermediates, and other signaling molecules to modulate host defense response (Pieterse and van Loon 1999). In rice, an increasing number of studies have shown that JA is able to induce phytoalexin production and expression of many defense-related genes (Agrawal et al. 2000a,b; Jwa et al. 2001; Lee et al. 2001; Moons et al. 1997; Rakwal and Komatsu 2000; Schweizer et al. 1997a,b, 1998; Tamogami et al. 1997; Xiong et al. 2001). For example, both exogenous JA treatment and $M$. grisea strongly induced rice

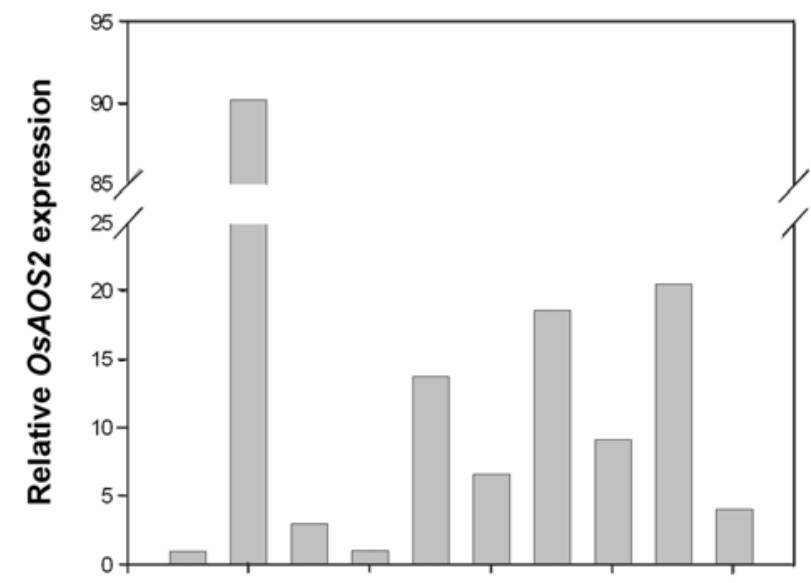

\section{$\frac{L \quad S \quad R}{2 \text { weeks }} \frac{L \quad S \quad R}{2 \text { months }}$ YP $P \quad C \quad F$}

Fig. 3. Differential expression of Oryza sativa allene oxide synthase $(O s A O S) 2$ in various parts of rice plants. The relative expression of OsAOS2 was determined by quantitative reverse-transcription polymerase chain reaction. $\mathrm{L}=$ leaves; $\mathrm{S}=$ sheath; $\mathrm{R}=$ roots; $\mathrm{YP}=$ young panicle; $\mathrm{P}=$ panicle; $\mathrm{C}=$ culm; and $\mathrm{F}=$ florets. Experiments were conducted twice with similar results.

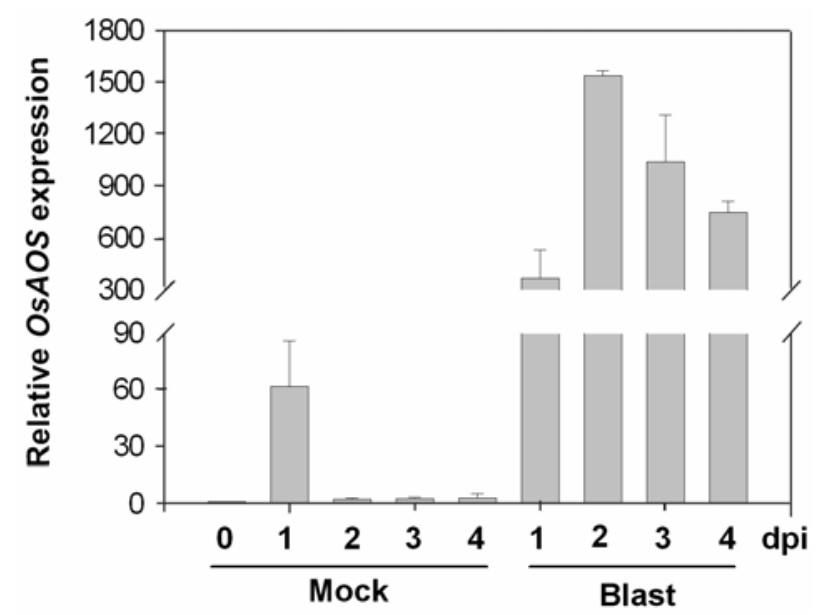

Fig. 4. Induction of Oryza sativa allene oxide synthase (OsAOS)2 following the infection of Magnaporthe grisea. The quantitative reverse-transcription polymerase chain reaction data were averaged from three independent samples. Experiments were conducted three times with similar results.
PR1 proteins as detected by using antisera raised against the major basic PR1 of tomato (Schweizer et al. 1997a). Furthermore, jasmonate biosynthesis inhibitors such as tetcyclacis significantly reduce endogenous JA levels in rice and inhibit $M$. grisea-induced PR1 accumulation, suggesting that endogenous JA is required for PR1 induction. Compared with mock treatments, paradoxically, infection of rice seedlings with $M$. grisea or Pseudomonas syringae pv. syringae (a nonpathogen) did not significantly enhance the endogenous levels of JA within $48 \mathrm{~h}$ after inoculation (Schweizer et al. 1997b). It is possible that other octadecanoid derivatives that are functionally similar to JA may act as major inducible molecules for induced resistance in rice. Previously, a couple of octadecanoid derivatives have been demonstrated to play a role in host defense against rice blast fungus (Kato et al. 1984; Song et al. 1994). In this study, however, a modest increase of endogenous JA (from 7.5 to $36 \mathrm{ng} / \mathrm{g}$ of $\mathrm{FW}$ ) was observed at 5 days after $M$. grisea infection. More extensive infection and lesion development at the late stage of infection might have contributed to the increased level of endogenous JA.

Schweizer and associates (1998) found that exogenous application of JA or wounding was able to induce disease resistance in systemic leaves but not in local, treated leaves. In contrast, we observed clear induction of $P R l$ gene and induced resistance in local, JA-treated leaves, rather than in systemic, untreated leaves. Such discrepancy may result from a number of experimental variables. Schweizer and associates (1997a,b, 1998) inoculated rice seedlings with a highly virulent isolate of $M$. grisea, which might have overcome JA-induced resistance. In our experiments, a moderately virulent isolate of $M$. grisea was used, which may allow the detection of local induced resistance. In addition to phenotypic measurement of lesion size and number, which often show considerable variations, we have

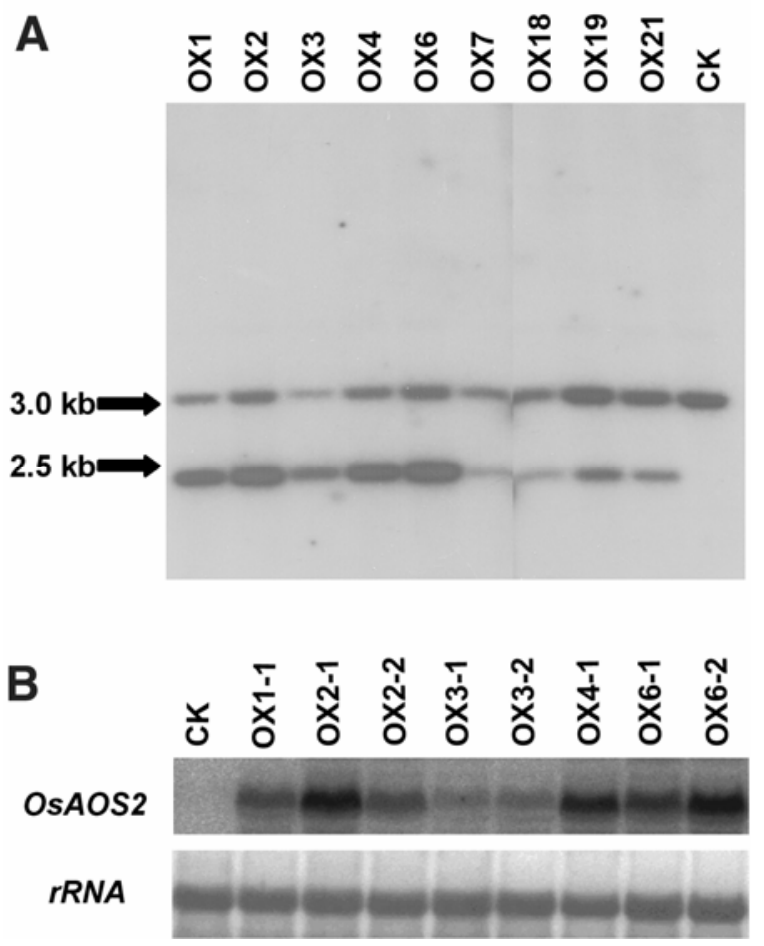

Fig. 5. Molecular analysis of Oryza sativa allene oxide synthase (OsAOS)2 overexpression lines. A, Southern blot analysis of representative transgenic lines. The genomic DNAs from leaves of control and transgenic plants were digested with EcoRI and probed with OsAOS 2 cDNA. OX = overexpression line and $\mathrm{CK}=$ control plant. B, RNA blot analysis of the OsAOS 2 inducible overexpression in transgenic lines 5 days after Magnaporthe grisea infection $(\mathrm{dpi}=$ days postinoculation $)$. 
quantified the relative growth of $M$. grisea in rice seedlings for more accurate assessment of disease severity.

There is strong evidence demonstrating that AOS is a key enzyme and a control point of the JA biosynthetic pathway in Arabidopsis, a model dicotyledonous species. For instance, AOS knock-out mutant is male sterile and the male sterility could be rescued by exogenous application of MeJA or by constitutive expression of functional $A O S$ in a complementation experiment (Park et al. 2002). The same was true for another Arabidopsis mutant called delayed-dehiscence2-2 (dde2-2) that has a frameshift mutation in the AOS gene (von Malek et al. 2002). Based on sequence analysis in this study, the OsAOS2 is very close to the AOS proteins from barley and wheat (approximately 70\% identity in amino acid level) (Fig. 1B). A common feature of these AOSs is lack of a signal peptide for targeting to the chloroplasts. In contrast, all AOSs from dicotyledonous species contain the chloroplast signal peptide, except rubber tree. OsAOS2 shares relatively low homology with AOSs of dicotyledonous species (approximately 50\%). However, like all other $A O S$ genes, the OSAOS 2 encodes four common domains (Fig. 2A, domains A-D) that are distinctive for the CYP74A family of cytochrome P450 proteins, which does not require oxygen, NADPH, and P450 reductase for enzymatic activity (Schaller 2001). Although four members (OsAOS1 to OsAOS4) of the small AOS gene family were

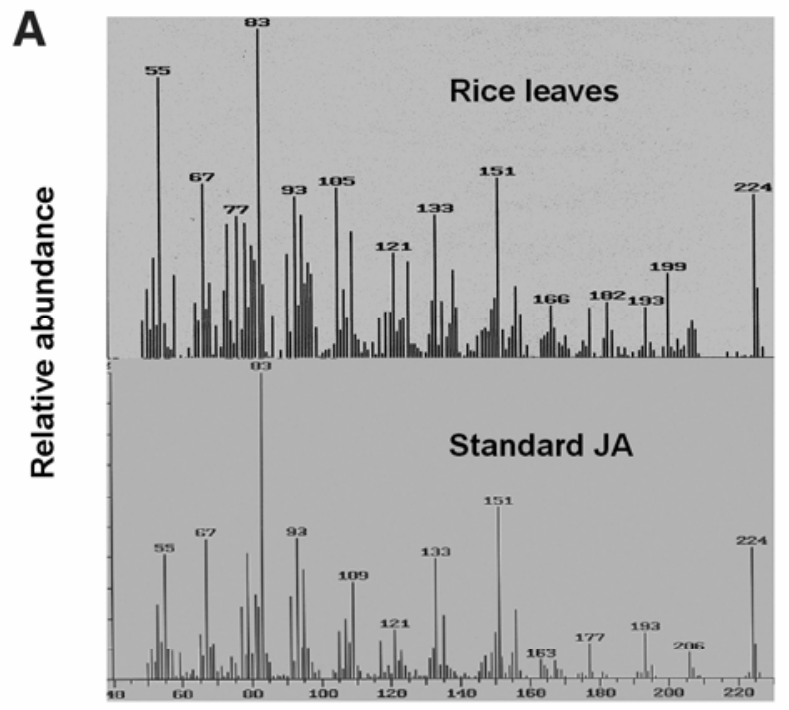

B

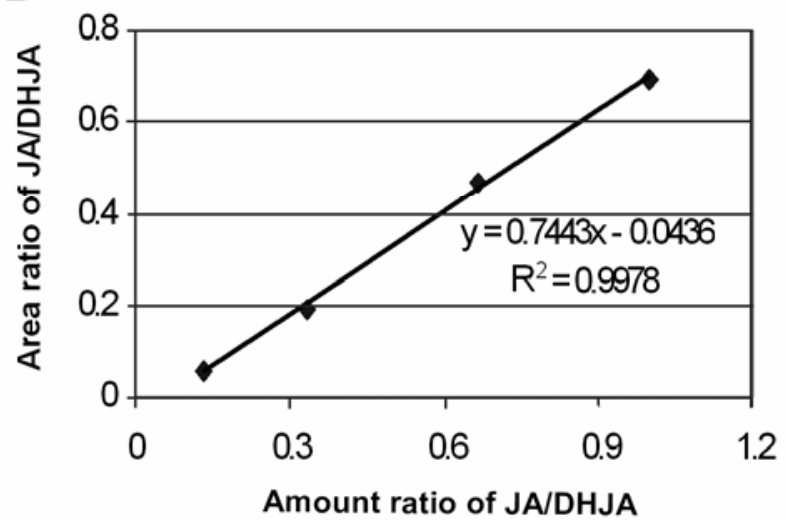

found in the rice genome (Haga and Iino 2004), OsAOS2 appears to be a single-copy gene based on our Southern blot analysis (Fig. 2B). This is consistent with the result of Agrawal and associates (2002) but differs from that of $\mathrm{Ha}$ and associates (2002), who reported two OsAOS2 copies due to the erroneous explanation of their Southern blot data. The sequence identity between OsAOS1 and OsAOS2 was only 55\% at the amino acid level. OSAOS1 was isolated by map-based cloning of the gene responsible for rice cpml mutant (which is impaired in the phytochrome-mediated inhibition of coleoptile growth and in the process of anthesis) and shown to be involved in phytochrome-mediated regulation of seedling growth (Haga and Iino 2004).

The expression level of plant $A O S$ genes often varies in different organs and tissues. For example, the $A O S$ transcripts were more abundant in the leaf and flower but much less in the root, stem, and silique of Arabidopsis (Laudert and Weiler 1998). High-level expression of $A O S$ also was detected in the achenes of flax (Song and Brash 1991), in flower (Sivasankar et al. 2000) and stem of tomato (Howe et al. 2000), and in scutellar nodule and leaf base of barley (Maucher et al. 2000). Compared with Arabidopsis and several other plant $A O S$ genes, the overall expression of OsAOS2 is rather low (even after the induction by $M$. grisea) and difficult to detect by RNA blot analysis. However, it does exhibit preferential expres-

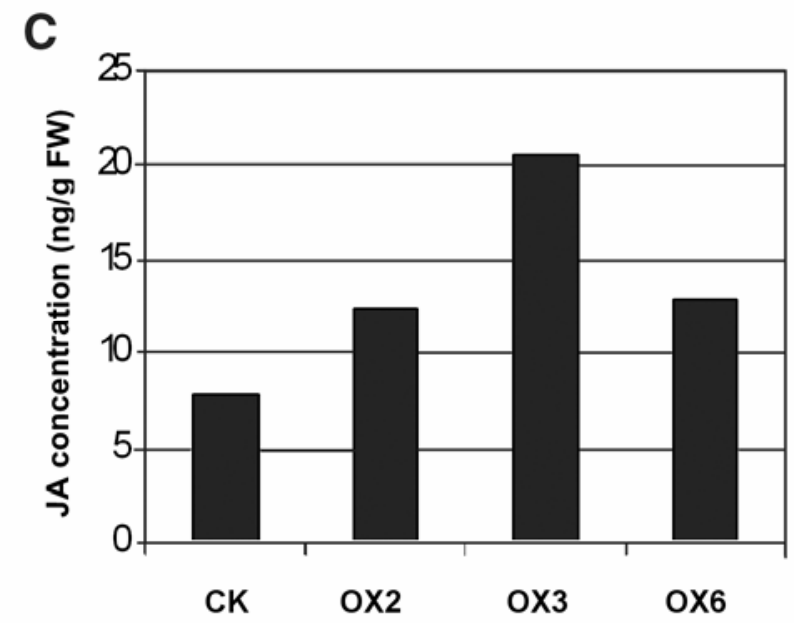

D

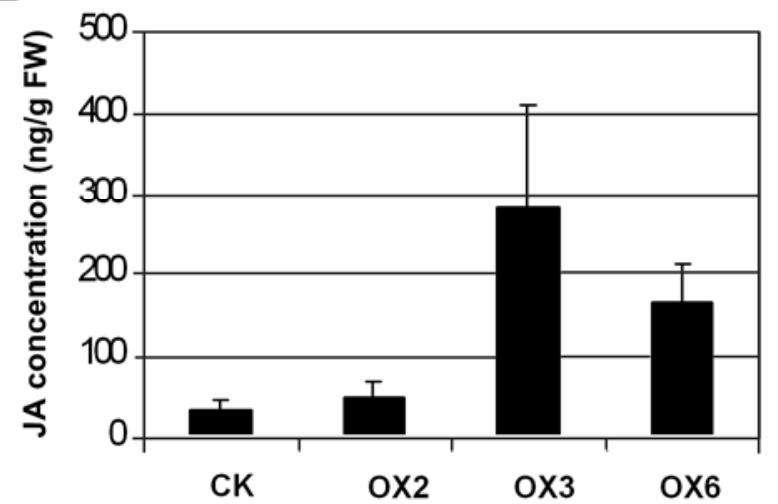

Fig. 6. Endogenous jasmonic acid (JA) levels in control and Oryza sativa allene oxide synthase (OsAOS)2 transgenic plants. A, Mass spectra of commercial JA standard and endogenous JA from rice leaf tissues. B, Standard curve derived from amount ratio versus area ratio of JA/9,10-dihydro jasmonic acid (DHJA). C, Endogenous JA levels in T2 plants of three overexpression lines. D, Endogenous JA levels in T2 transgenic plants 5 days after Magnaporthe grisea infection. The data were averaged from three independent samples with standard error. 
sion in sheath, culm, and flower tissues of rice plants. Quantitative RT-PCR assays also revealed that OsAOS2 was significantly activated in rice leaves by the infection of $M$. grisea, suggesting its potential involvement in the rice-pathogen interaction and defense response. However, our study indicated that OsAOS 2 was not induced by wounding or JA. In contrast, the expression of most plant $A O S$ genes are positively regulated by wounding or JA (Harms et al. 1995; Park et al. 2002; Ziegler et al. 2001). It is possible that a high basal level of SA in rice plants may have inhibited the OSAOS 2 expression and reduced the endogenous JA level in rice (5 to $10 \mathrm{ng} / \mathrm{g}$ of $\mathrm{FW}$ for the basal level and 10 to $40 \mathrm{ng} / \mathrm{g}$ of $\mathrm{FW}$ after wounding) (this study; Schweizer et al. 1997a,b, 1998) that is much lower than that of Arabidopsis (10 to $100 \mathrm{ng} / \mathrm{g}$ of FW for the basal level and 1,000 to 2,000 ng/g of FW after wounding) (Kubigsteltig and Weiler 2003; Park et al. 2000) and flax (approximately $100 \mathrm{ng} / \mathrm{g}$ of FW for the basal level and approximately 1,000 ng after wounding) (Harms et al. 1998). Tomato plants that contain a relatively high level of endogenous SA also appear to have relatively low levels of JA (approximately $2.5 \mathrm{ng} / \mathrm{g}$ of FW for the basal level and approximately $50 \mathrm{ng} / \mathrm{g}$ of FW after wounding) (Li et al. 2002). This is consistent with previous reports in flax and tomato that exogenous SA can significantly inhibit JA- or wounding-induced AOS expression (Harms et al. 1998; Sivasankar et al. 2000). Indeed, in SA-deficient rice plants (Yang et al. 2004), we observed a significant increase of OsAOS2 expression in the absence or presence of $M$. grisea infection (Y. Yang, unpublished data).

Previously, overexpression of $A O S$ genes under the control of constitutive CaMV $35 S$ promoter has been reported in potato, tobacco, and Arabidopsis transgenic plants (Harms et al. 1995; Laudert et al. 2000; Wang et al. 1999). Constitutive overexpression of $A O S$ in Arabidopsis and tobacco did not increase the basal level of JA; however, the transgenic lines exhibited
A

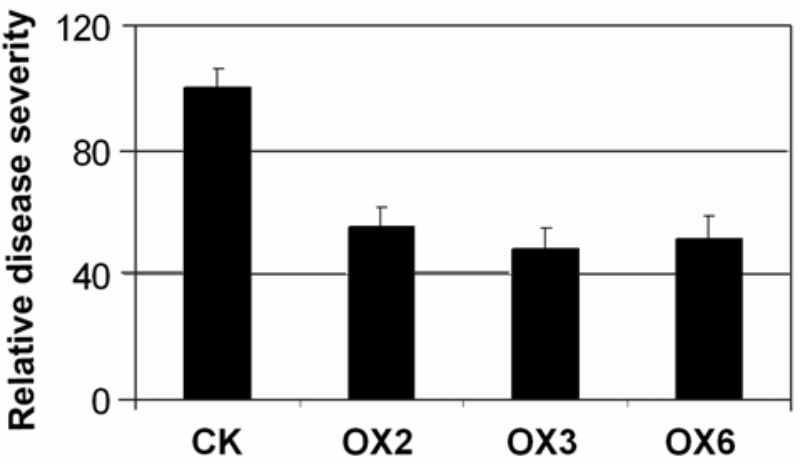

B

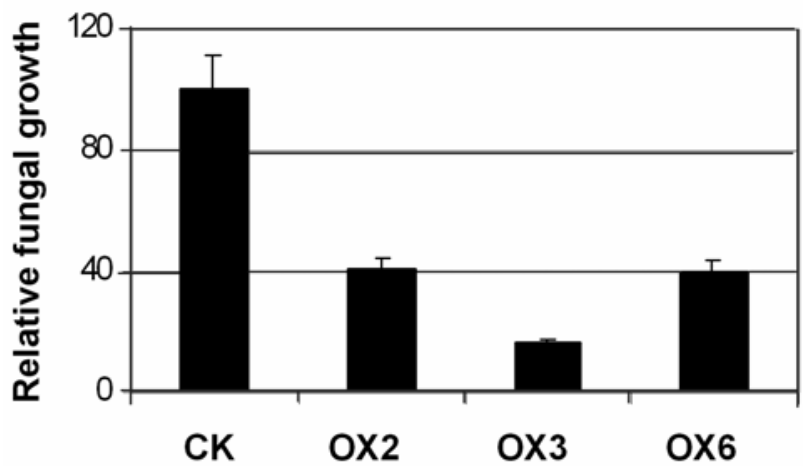

Fig. 8. Increased tolerance of Oryza sativa allene oxide synthase (OsAOS)2 overexpression lines to Magnaporthe grisea infection. A, Blast disease evaluation according to the rating scale of Marchetti and associates (1976) and presented as relative disease severity. B, Disease severity measurement based on the relative fungal growth of $M$. grisea.
A

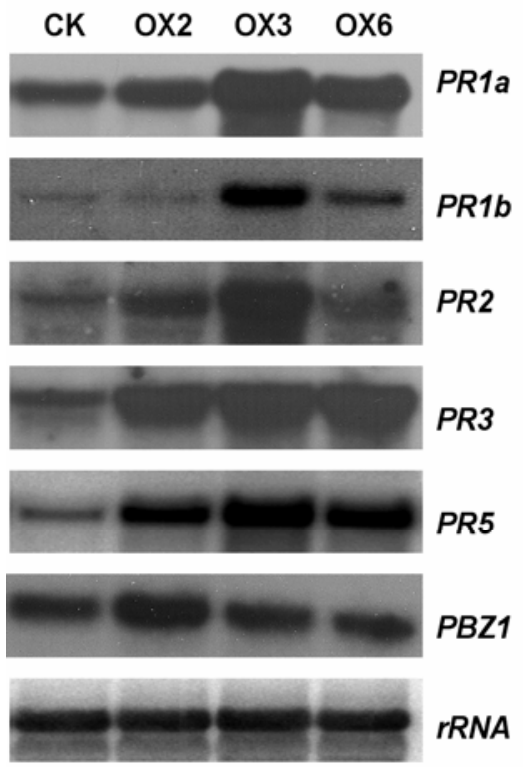

B
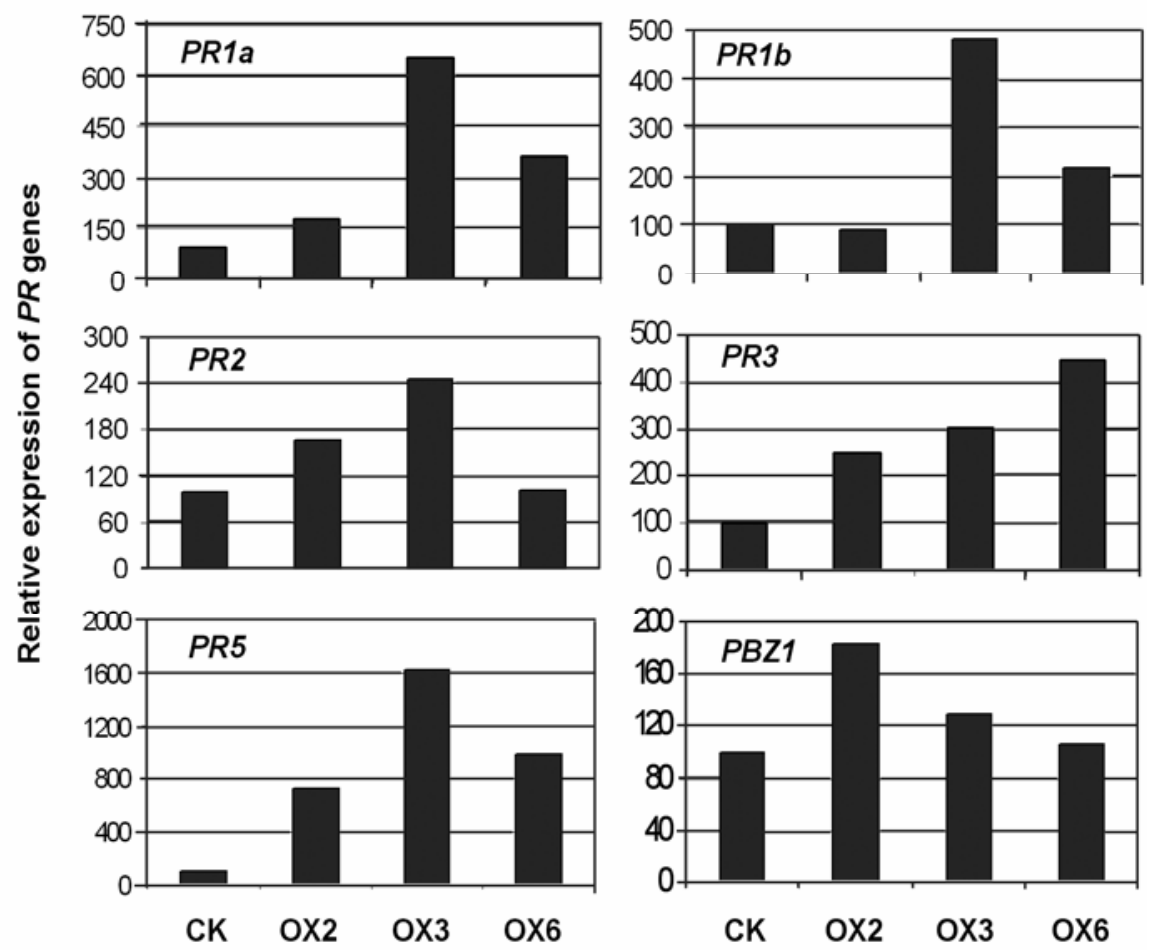
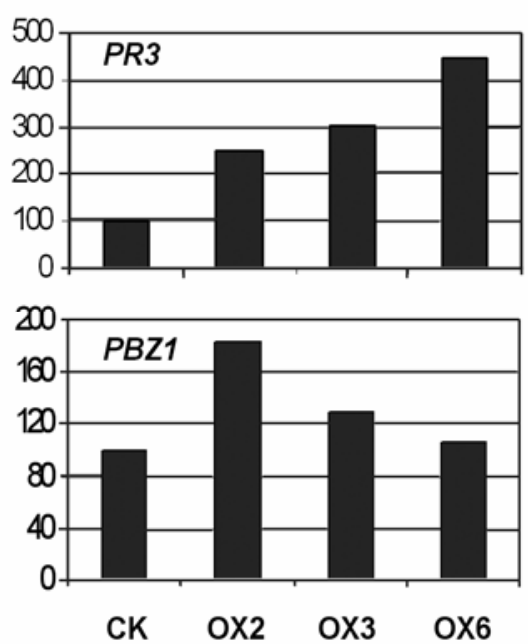

Fig. 7. Enhanced expression of rice pathogenesis-related $(P R)$ genes in Oryza sativa allene oxide synthase $(O s A O S) 2$ overexpression lines. The stress-inducible PBZ1 promoter::OSAOS2 in transgenic plants was moderately activated by placing leaf segments in deionized water under continuous light at $25^{\circ} \mathrm{C}$ for 24 h. Total RNAs were isolated from control and transgenic leaf segments for $\mathbf{A}$, Northern analysis and $\mathbf{B}$, phosphoimaging quantification. 
an earlier JA peak and higher levels of JA than the control plant after wounding (Laudert et al. 2000; Wang et al. 1999). In contrast, transgenic potato overexpressing $A O S$ showed a higher level of endogenous JA but did not activate the expression of JA-responsive genes such as the proteinase inhibitor gene (Harms et al. 1995). It was suggested that the constitutive and a higher basal level of JA might not act as an effective signal, but that the relative increase of JA in a short period of time is more critical for the induction of JA-responsive genes (Schaller 2001). From this point of view, overexpression of $A O S$ under the control of an inducible promoter might be better than the use of a constitutive promoter. In this study, we have generated and characterized transgenic rice lines with overexpression of OsAOS 2 under the control of a strong, pathogen-inducible $P B Z 1$ promoter. Compared with the control plant, transgenic rice lines exhibited a significant increase of endogenous JA level, especially after the infection with $M$. grisea (Fig. 6C and D). More importantly, we were able to demonstrate that such an increase in OSAOS2 transcripts and endogenous JA resulted in the activation of many JA-responsive $P R$ genes (Fig. 7). Furthermore, the increase of endogenous JA and stronger induction of $P R$ genes appear to be translated into the enhanced resistance of transgenic rice to the blast fungus. As a result, our study not only shows for the first time the function of an $A O S$ gene in the biosynthesis of JA in monocotyledonous species, but also demonstrates the importance of JA in mediating rice $P R$ gene expression and disease resistance.

We noticed that the OSAOS 2 transcript level, JA content, and $P R$ gene expression were not proportionally correlated with one another among the overexpression lines. Due to the use of the pathogen-inducible $P B Z 1$ promoter (rather than a constitutive promoter), induction of $O S A O S 2$ transgene by $M$. grisea might vary considerably among different leaves and plants of a particular transgenic line. A relatively large quantity of leaf samples from different seedlings of each transgenic line were required for JA quantification (Fig. 6D); however, a single seedling of a particular line was used for the RNA blot (Fig. 5B), which might skew the correlation between $O s A O S 2$ expression and JA level. In addition, the potential activation of other $A O S$ genes and post-transcriptional events (e.g., efficiency of protein translation, protein stability, and enzyme activity) might account for the discrepancy between the OsAOS2 transcript level and JA content.

To further determine the role of OsAOS2 and octadecanoid pathway in rice defense gene expression and induced resistance, we also have generated OsAOS2 suppression lines using doublestranded RNA interference (C. Mei and Y. Yang, unpublished). However, suppression of OsAOS2 (which already has a low level of basal expression in wild-type rice plants) did not significantly reduce the JA level and disease resistance of the transgenic rice RNAi lines. Because the rice genome contains four $A O S$ genes, it is likely that other $A O S$ members may have compensated for the defect of OSAOS 2 in the RNAi lines. We are now in the process of generating rice RNAi lines with the suppression of two or more $A O S$ genes. We have also generated rice RNAi lines that are insensitive to JA and other octadecanoid derivatives. Hopefully, these RNAi lines will further aid in the elucidation of JA- or octadecanoid-mediated resistance response in rice plants in the near future.

\section{MATERIALS AND METHODS}

\section{Sequence analysis of $O s A O S 2$ cDNA.}

The OsAOS 2 gene was provided as an expressed sequence tag clone by the Japanese Rice Genomics Program. The fulllength of OsAOS2 cDNA was sequenced completely with the primer-walking approach in the DNA core facility at the Uni- versity of Arkansas. Sequence analysis was conducted using the Vector NTI 6.0 software (InforMax Inc., MD, U.S.A.) and the BLAST program from the National Center for Biotechnology Information.

OsAOS2 overexpression construct and rice transformation.

The overexpression construct, $P B Z 1:: O s A O S 2$, was made by directly inserting the full-length OsAOS2 cDNA into the pCAMBIA1300 vector containing the pathogen-inducible rice $P B Z 1$ promoter (Lee 2002). The PBZ1::OsAOS2 construct was introduced into Agrobacterium tumefaciens strain EHA105 by electroporation. Subsequent transformation was conducted using rice (Oryza sativa L.) cv. Nipponbare according to a modified method of Hiei and associates (1994) as described previously (Xiong and Yang 2003).

\section{Plant materials and fungal isolates.}

The wild-type Nipponbare cultivar as well as the OsAOS2 transgenic plants were grown in Redi Earth soil mix (Hummert International, Springfield, MO, U.S.A.) in a $28^{\circ} \mathrm{C}$ greenhouse with a light-and-dark cycle of 14 and $10 \mathrm{~h}$, respectively. Plants were fertilized with $0.5 \%$ ammonium sulfate every 2 weeks until flowering. For transgenic plants confirmed with Southern blot analysis, self-pollinated seed from independent transgenic lines were harvested individually. $\mathrm{T} 1$ and $\mathrm{T} 2$ plants carrying the transgene were selected based on hygromycin resistance and maintained as described previously (Xiong and Yang 2003). A moderately virulent isolate (18-1, IC-17 pathotype) of $M$. grisea was used to inoculate rice seedlings (Harp and Correll 1998).

\section{Pathogen inoculation and chemical treatments.}

For $M$. grisea infection, the 2-week-old plants were spray inoculated with the fungal conidial spores at a concentration of $2.5 \times 10^{5}$ spores $/ \mathrm{ml}$ (Lee et al. 2001). After incubation in a dew chamber at $22^{\circ} \mathrm{C}$ for $24 \mathrm{~h}$, rice seedlings were moved to a $28^{\circ} \mathrm{C}$ growth chamber with $14 \mathrm{~h}$ of light. For mock treatment, rice seedlings were sprayed with water. Leaf samples were taken at $0,1,2,3$, and 4 days after fungal inoculation.

Chemical activation of induced resistance in rice was conducted by spraying rice seedlings with $\mathrm{H}_{2} \mathrm{O}$, SA $(1.5 \mathrm{mM})$, JA (0.1 mM), PBZ (0.25 mM), or BTH $(0.25 \mathrm{mM})$. Approximately 125 to 5002 -week-old seedlings with a near-fully expanded third leaf were used for each experiment. Three days later, chemical-treated rice plants were spray inoculated with $M$. grisea at the concentration of $2.5 \times 10^{5}$ spores $/ \mathrm{ml}$. Disease severity on the third leaves of each plant was measured at 6 days after inoculation. Each leaf was scored for the number of necrotic lesions and size of the three largest lesions. Subsequently, the same leaves were collected for total DNA extraction and quantification of $M$. grisea growth based on its $r D N A$ content in rice tissues (Qi and Yang 2002).

\section{DNA and RNA blot analyses.}

Genomic DNA was extracted from rice leaves according to the previously described method (Qi and Yang 2002) and digested with appropriate restriction enzymes. Digested DNA samples were separated in a $0.7 \%$ agarose gel at $30 \mathrm{~V}$ overnight and blotted onto a nylon membrane using the standard protocol (Sambrook et al. 1989). The total RNA was extracted from rice tissues using the TRIzol reagent (Invitrogen, Carlsbad, CA, U.S.A.). Total RNAs (10 $\mu$ g each) were fractionated on a $1.2 \%$ agarose gel containing formaldehyde and blotted onto a nylon membrane. For Southern and Northern hybridization, gene-specific probes were labeled with $\left[\alpha{ }^{-32} \mathrm{P}\right] \mathrm{dCTP}$ using the random-priming kit (Promega Corp., Madison, WI, U.S.A.). Hybridization of DNA and RNA blots was carried out overnight 
with PerfectHyb Plus hybridization buffer (Sigma-Aldrich, St. Louis) at $62^{\circ} \mathrm{C}$. Subsequently, blots were washed with $2 \times \mathrm{SSC}$ ( $1 \times \mathrm{SSC}$ is $0.15 \mathrm{M} \mathrm{NaCl}$ plus $0.015 \mathrm{M}$ sodium citrate) twice for $10 \mathrm{~min}$, then $0.5 \times \mathrm{SSC}$ and $0.5 \%$ sodium dodecyl sulfate twice for $20 \mathrm{~min}$ at $62^{\circ} \mathrm{C}$. Relative levels of gene expression were quantified with a phosphoimaging system (Molecular Dynamics, Sunnyvale, CA, U.S.A.).

To prepare the $P R$ gene probe, gene-specific fragments were amplified by PCR using the following specific pairs of primers: PRla forward primer, 5'-TCG AGC AGG TTA TCC TGC TGC TTG-3' and reverse primer, 5'-GAG TAG TTG CAG GTG ATG AAG ACG-3' (accession number: AJ278436; Agrawal et al. 2000a); $P R 2$ forward primer, 5'-ACA TCA AGG TGA CGA CGT CG-3' and reverse primer, 5'-ATC AGA AGC TGA TGG GGT AG -3' (accession number: X58877; Simmons et al. 1992); PR3 forward primer, 5'-TAC TGT GTC CAG AGC TCG CAG TGG-3' and reverse primer, 5'-TCT GGT TGT AGC AGT CCA AGT TGG-3' (accession number: X87109; $\mathrm{Xu}$ et al. 1996); and PR5 forward primer, 5'-ACC TCT TCC GCT GTC CTC-3' and reverse primer, 5'-GAA GAC GAC TTG GTA GTT GC-3' (accession number: X68197; Agrawal et al. 2003). All PCR-amplified fragments were first cloned into pGEM-T Easy vector (Promega Corp.) and verified by DNA sequencing. The $P R I b$ and $P B Z 1$ genes were provided by the Japanese Rice Genomics Program and described previously (Yang et al. 2004).

\section{Quantitative RT-PCR for OsAOS2 expression.}

The total RNA was isolated from rice tissues and treated with RNase-free DNase I (Promega Corp.) to remove the trace DNA in RNA samples. Reverse transcription was carried with M-MuLV reverse transcriptase (New England BioLab, Beverly, MA, U.S.A.) according to the manufacturer's instructions. Quantitative real-time PCR was conducted in the Mx3000P real-time PCR system (Stratagene, La Jolla, CA, U.S.A.) with the QuantiTect SYBR Green PCR kit (Qiagen, Valencia, CA, U.S.A.). The following specific pair of primers was used to detect the OsAOS 2 expression: forward primer, 5'-AGC TAG CTA GAA GAG AGT TAG C-3' and reverse primer, 5'-ACT CGA AGT ACT TGT CCT GC-3'. The quantitative RT-PCR and relative expression of OsAOS2 was normalized using the rice ubiquitin 1 gene (amplified with forward primer 5'-GTG GCC AGT AAG TCC TCA GC-3' and reverse primer 5'-GAA ACG GGA CAC GAC CAA GG-3').

\section{Analysis of endogenous JA levels by GC-MS.}

Endogenous JA levels in rice tissues were determined by GC-MS following the methods of Weber and associates (1997), Li and associates (2002), and Gundlach and associates (1992), with several major modifications. Briefly, approximately $1 \mathrm{~g}$ of leaf tissues was ground to fine powder with liquid nitrogen. Ice-cold methanol $(10 \mathrm{ml})$ and $150 \mathrm{ng}$ of DHJA (as an internal standard, made by Olchemim, Olomouc, Czech Republic) were added to the powder. After rotary shaking in a $4^{\circ} \mathrm{C}$ cold room overnight, ice-cold water was added (to the final methanol concentration of $70 \%$ ) and mixed with the sample. The mixture was centrifuged at $5,000 \mathrm{rpm}$ for $10 \mathrm{~min}$ at $4^{\circ} \mathrm{C}$ and supernatant was further filtered through a $0.45-\mu \mathrm{M}$ membrane. The filtrate was adjusted to $\mathrm{pH} 8.5$ with $0.1 \mathrm{M}$ of $\mathrm{NH}_{4} \mathrm{OH}$ and loaded to a reverse phase C18 column (J. T. Baker) which had been conditioned with methanol and then $70 \%$ methanol, and then washed with an additional $75 \%$ methanol. All of the run-through solution, added with water to make a methanol concentration less than $20 \%$, was adjusted to $\mathrm{pH}$ 3.5 with $10 \%$ formic acid. Jasmonates were partitioned three times with chloroform. The chloroform phase was dehydrated with $\mathrm{Na}_{2} \mathrm{SO}_{4}$ and dried down with nitrogen gas at $35^{\circ} \mathrm{C}$. For derivatization of JA and DHJA, we found that boron trifluoride (BF3)/methanol (14\% wt/vol) (Alltech Associates, Inc., Deerfield, IL, U.S.A.) was a good derivatization agent for JA quantification of rice leaves. Therefore, $75 \mu \mathrm{l}$ of BF3/methanol were added to the above dried-down samples for derivatization at $70^{\circ} \mathrm{C}$ for $1 \mathrm{~h}$, following by the addition of $450 \mu \mathrm{l}$ of saturated $\mathrm{NaCl}$ and $1 \mathrm{ml}$ of hexane. The JA and DHJA derivatives were partitioned into hexane phase by mixing and spinning and hexane phase was dried down with nitrogen gas at $35^{\circ} \mathrm{C}$. Hexane $(30 \mu \mathrm{l})$ was added to dissolve the derivatives and $2 \mu \mathrm{l}$ were used for injection. JA detection was carried in GC-MS (Varian 3400, Saturn 4D GC/MS with FactorFour capillary column VF-5MS, $0.25 \mathrm{mM}$ by $0.25 \mu \mathrm{M}$ by $30 \mathrm{M}$ ) under the condition of $77^{\circ} \mathrm{C}$ for $1.2 \mathrm{~min}, 10^{\circ} \mathrm{C} / \mathrm{min}$ for $10 \mathrm{~min}, 180^{\circ} \mathrm{C}$ for $4 \mathrm{~min}, 40^{\circ} \mathrm{C} / \mathrm{min}$ to $280^{\circ} \mathrm{C}$, and finally $280^{\circ} \mathrm{C}$ for $6 \mathrm{~min}$. JA quantification was carried out using a standard curve of area ratio versus amount ratio of JA and DHJA.

\section{ACKNOWLEDGMENTS}

This work was supported by the grants from USDA/NRI (2003-3531913511) and the Arkansas Rice Research and Promotion Board. We would like to thank the Japanese Rice Genomic Program for providing OsAOS2, $P R 1 b$, and PBZ1 EST clones, and J. Mattice and S. Zhang for assistance in JA quantification with GC-MS.

\section{LITERATURE CITED}

Agrawal, G. K., Jwa, N. S., and Rakwal, R. 2000a. A novel rice (Oryza sativa L.) acidic PR1 gene highly responsive to cut, phytohormones, and protein phosphatase inhibitors. Biochem. Biophys. Res. Commun. 274:157-165.

Agrawal, G. K., Rakwal, R., and Jwa, N. S. 2000b. Rice (Oryza sativa L.) $O s P R 1 b$ gene is phytohormonally regulated in close interaction with light signals. Biochem. Biophys. Res. Commun. 278:290-298.

Agrawal, G. K., Rakwal, R., Jwa, N. S., Han, K. S., and Agrawal, V. P. 2002. Molecular cloning and mRNA expression analysis of the first rice jasmonate biosynthetic pathway gene allene oxide synthase. Plant Physiol. Biochem. 40:771-782.

Agrawal, G. K., Rakwal, R., and Jwa, N. S. 2003. Differential inductin of three pathogenesis-related genes, $P R 10, P R 1 b$ and $P R 5$ by the ethylene generator ethephon under light and dark in rice (Oryza sativa L.) seedlings. J. Plant Physiol. 158:133-137

Agrawal, G. K., Tamogami, S., Han, O., Iwahashi, H., and Rakwal, R. 2004. Rice octadecanoid pathway. Biochem. Biophys. Res. Commun. 317:1-15.

Cohen, Y., Gisi, U., and Niderman, T. 1993. Local and systemic protection against Phytophthora infestans induced in potato and tomato plants by jasmonic acid and jasmonic-methyl-ester. Phytopathology 83:10541062

Creelman, R. A., and Mullet, J.E. 1997. Biosynthesis and action of jasmonates in plants. Annu. Rev. Plant Physiol. Plant Mol. Biol. 48:355381.

Dong, X. 1998. SA, JA, ethylene, and disease resistance in plants. Curr. Opin. Plant Biol. 1:316-323.

Ellis, C., and Turner, J. G. 2001. The Arabidopsis mutant cev1 has constitutively active jasmonate and ethylene signal pathways and enhanced resistance to pathogens. Plant Cell 13:1025-1033.

Ellis, C., Karafyllidis, I., Wasternack, C., and Turner, J. G. 2002. The Arabidopsis mutant cev1 links cell wall signaling to jasmonate and ethylene responses. Plant Cell 14:1557-1566.

Farmer, E. E., Almeras, E., and Krishnamurthy, V. 2003. Jasmonates and related oxylipins in plant responses to pathogenesis and herbivory. Curr. Opin. Plant Biol. 6:372-378.

Feys, B., Benedetti, C. E., Penfold, C. N., and Turner, J. G. 1994. Arabidopsis mutants selected for resistance to the phytotoxin coronatine are male sterile, insensitive to methyl jasmonate, and resistant to a bacterial pathogen. Plant Cell 6:751-759.

Gundlach, H., Müller, M. J., Kutchan, T., and Zenk, M. H. 1992. Jasmonic acid is a signal transducer in elicitor-induced plant cell cultures. Proc. Natl. Acad. Sci. U.S.A. 89:2389-2393.

Ha, S. B., Lee, B. C., Lee, D. E., Kuk, Y. I., Lee, A. Y., Han, O., and Back, K. 2002. Molecular characterization of the gene encoding rice allene oxide synthase and its expression. Biosci. Biotechnol. Biochem. $66: 2719-2722$. 
Haga, H., and Iino, M. 2004. Phytochrome-mediated transcriptional upregulation of allene oxide synthase in rice seedlings. Plant Cell Physiol. 45:119-128.

Harms, K., Atzorn, R., Brash, A., Kühn, H., Wasternack, C., Willmitzer, L., and Peña-Cortés, H. 1995. Expression of a flax allene oxide synthase cDNA leads to increased endogenous jasmonic acid levels in transgenic potato plants but not to a corresponding activation of JAresponding genes. Plant Cell 7:1645-1654.

Harms, K., Ramirez, I., and Peña-Cortés, H. 1998. Inhibition of woundinduced accumulation of allene oxide synthase transcripts in flax leaves by aspirin and salicylic acid. Plant Physiol. 118:1057-1065.

Harp, T. L., and Correll, J. C. 1998. Recovery and characterization of spontaneous, selenate-resistant mutants of Magnaporthe grisea, the rice blast pathogen. Mycologia 90:954-963.

He, Y., Fukushige, H., Hildebrand, D. F., and Gan, S. 2002. Evidence supporting a role of jasmonic acid in Arabidopsis leaf senescence. Plant Physiol. 128:876-884.

Hiei, Y., Ohta, S., Komari, T., and Kumashiro, T. 1994. Efficient transformation of rice (Oryza sativa L.) mediated by Agrobacterium and sequence analysis of the boundaries of the T-DNA. Plant J. 6:271-282.

Howe, G. A., Lee, G. I., Itoh, A., Li, L., and DeRocher, A. E. 2000. Cytochrome P450-dependent metabolism of oxylipins in tomato. Cloning and expression of allene oxide synthase and fatty acid hydroperoxide lyase. Plant Physiol. 123:711-724.

Howe, G. A., and Ryan, C. A. 1999. Suppressors of systemin signaling identify genes in the tomato wound response pathway. Genetics 153:1411-1421.

Howe, G. A., and Schilmiller, A. L. 2002. Oxylipin metabolism in response to stress. Curr. Opin. Plant Biol. 5:230-236.

Jwa, N. S., Agrawal G. K., Rakwal, R., Park, C. H., and Agrawal, V. P. 2001. Molecular cloning and characterization of a novel jasmonate inducible pathogenesis-related class 10 protein gene, JIOsPR10, from rice (Oryza sativa L.) seedling leaves. Biochem. Biophys. Res. Commun. 286:973-983.

Kato, T., Yamaguchi, Y., Hirano, T., Yokoyama, T., and Uyehara, T. 1984 Unsaturated hydroxy fatty acids, the self defensive substances in rice plant against rice blast disease (Pyricularia oryzae). Chem. Lett. 3:409-412.

Kessler, A., Halitschke, R., and Baldwin, I.T. 2004. Silencing the jasmonate cascade: Induced plant defense and insect populations. Science 305:665-668.

Kubigsteltig, I., Laudert, D., and Weiler, E. W. 1999. Structure and regulation of the Arabidopsis thaliana allene oxide synthase gene. Planta 208:463-471.

Kubigsteltig, I., and Weiler, E. W. 2003. Arabidopsis mutants affected in the transcriptional control of allene oxide synthase, the enzyme catalyzing the entrance step in octadecanoid biosynthesis. Planta 217:748-757.

Laudert, D., Pfannschmidt, U., Lottspeich, F., Holländer-Czytko, H., and Weiler, E. W. 1996. Cloning, molecular and functional characterization of Arabidopsis thaliana allene oxide synthase (CYP74), the first enzyme of the octadecanoid pathway to jasmonates. Plant Mol. Biol. 31:323-335

Laudert, D., Schaller, F., and Weiler, E. W. 2000. Transgenic Nicotiana tabacum and Arabidopsis thaliana plants overexpressing allene oxide synthase. Planta 211:163-165.

Laudert, D., and Weiler, E. W. 1998. Allene oxide synthase: a major control point in Arabidopsis thaliana octadecanoid signaling. Plant J. 15:675-684

Lee, M. W. 2002. Molecular characterization and functional analysis of a pathogen-inducible rice $m y b$ gene. Ph.D. dissertation, University of Arkansas, Fayetteville, U.S.A.

Lee, M. W., Qi, M., and Yang, Y. 2001. A novel jasmonic acid-inducible rice $m y b$ gene associates with fungal infection and host cell death. Mol. Plant-Microbe Interact. 14:527-535.

Li, L., Li, C., and Howe, G. A. 2001. Genetic analysis of wound signaling in tomato. Evidence for a dual role of jasmonic acid in defense and female fertility. Plant Physiol. 127:1414-1417.

Li, L., Li, C., Lee, G. I., and Howe, G. A. 2002. Distinct roles for jasmonate synthesis and action in the systemic wound response of tomato. Proc. Natl. Acad. Sci. U.S.A. 99:6416-6421.

Liechti, R., and Farmer, E. E. 2003. The jasmonate biochemical pathway. Sci. STKE 203:CM18.

Marchetti, M. A., Rush, M. C., and Hunter, W. E. 1976. Current status of rice blast (Pyricularia oryzae) in the southern United States. Plant Dis. Rep. 60:721-725.

Maucher, H., Hause, B., Feussner, I., Ziegler, J., and Wasternack, C. 2000 Allene oxide synthases of barley (Hordeum vulgare cv. Salome): Tissue specific regulation in seedling development. Plant J. 21:199-213.

Midoh, N., and Iwata, M. 1996. Cloning and characterization of a probenazole-inducible gene for an intracellular pathogenesis-related protein in rice. Plant Cell Physiol. 37:9-18.
Moons, A., Prinsen, E., Bauw, G., and Montagu, M. van 1997. Antagonistic effects of abscisic acid and jasmonates on salt stress-inducible transcripts in rice roots. Plant Cell 9:2243-2259.

Nojiri, H., Sugimori, M., Yamane, H., Nishimura, Y., Yamada, A., Shibuya, N., Kodama, O., Murofushi, N., and Omori, T. 1996. Involvement of jasmonic acid in elicitor-induced phytoalexin production in suspensioncultured rice cells. Plant Physiol. 110:387-392.

Pan, Z., Durst, F., Werck-Reichhart, D., Gardner, H. W., Camara, B., Cornish, K., and Backhaus, R. A. 1995. The major protein of guayule rubber particles is a cytochrome $\mathrm{P} 450$. Characterization based on cDNA cloning and spectroscopic analysis of the solubilized enzyme and its reaction products. J. Biol. Chem. 270:8487-8494.

Park, J.-H., Halitschke, R., Kim, H. B., Baldwin, I. T., Feldmann, K. A., and Feyereisen, R. 2002. A knock-out mutation in allene oxide synthase results in male sterility and defective wound signal transduction in Arabidopsis due to a block in jasmonic acid biosynthesis. Plant J. 31:1-12.

Penninckx, I. A. M. A., Eggermont, K., Terras, F. R. G., Thomma, B. P. H. J., Samblanx, G. W. de, Buchala, A., Metraux, J. P., Manners, J. M., and Broekaert, W. F. 1996. Pathogen-induced systemic activation of a plant defensin gene in Arabidopsis follows a salicylic acid-independent pathway. Plant Cell 8:2309-2323.

Pieterse, C. M. J., and van Loon, L. C. 1999. Salicylic acid-independent plant defence pathways. Trends Plant Sci. 4:52-58.

Qi, M., and Yang, Y. 2002. Quantification of Magnaporthe grisea during infection of rice plants using real-time polymerase chain reaction and northern blot/phosphoimaging analyses. Phytopathology 92:870-876.

Rakwal, R., and Komatsu, S. 2000. Role of jasmonate in rice (Oryza sativa L.) self-defense mechanism using proteome analysis. Electrophoresis 21:2492-2500.

Reymond, P., and Farmer, E. E. 1998. Jasmonate and salicylate as global signals for defense gene expression. Curr. Opin. Plant Biol. 1:404-411.

Sambrook, J., Fritsch, E. F., and Maniatis, T. 1989. Molecular Cloning: A Laboratory Manual, 2nd ed. Cold Spring Harbor Laboratory Press, Cold Spring Harbor, NY, U.S.A.

Sanders, P. M., Lee, P. Y., Biesgen, C., Boone, J. D., Beals, T. P., Weiler, E. W., and Goldberg, R. B. 2000. The Arabidopsis DELAYED DEHIS$C E N C E 1$ gene encodes an enzyme in the jasmonic acid synthesis pathway. Plant Cell 12:1041-61.

Sasaki, Y., Asamizu, E., Shibata, D., Nakamura, Y., Kaneko, T., Awai, K., Amagai, M., Kuwata, C., Tsugane, T., Masuda, T., Shimada, H., Takamiya, K., Ohta, H., and Tabata, S. 2001. Monitoring of methyl jasmonate-responsive genes in Arabidopsis by cDNA macroarray: Selfactivation of jasmonic acid biosynthesis and crosstalk with other phytohormone signaling pathways. DNA Res. 8:153-161.

Schaller, F. 2001. Enzymes of the biosynthesis of octadecanoid-derived signaling molecules. J. Exp. Bot. 52:11-23.

Schweizer, P., Buchala, A., and Métraux. J.-P. 1997a. Gene-expression patterns and levels of jasmonica acid in rice treated with the resistance inducer 2, 6-dichloroisonicotinic acid. Plant Physiol. 115:61-70.

Schweizer, P., Buchala, A., Silverman, P., Seskar, M., Raskin, I., and Métraux, J.-P. 1997b. Jasmonate-inducible genes are activated in rice by pathogen attack without a concomitant increase in endogenous jasmonic acid levels. Plant Physiol. 114:79-88.

Schweizer, P., Buchala, A., Dudler, R., and Métraux, J.-P. 1998. Induced systemic resistance in wounded rice plants. Plant J. 14:475-481.

Simmons, C. R., Litts, J. C., Huang, N., and Rodriguez, R. L. 1992. Structure of a rice beta-glucanase gene regulated by ethylene, cytokinin, wounding, salicylic acid and fungal elicitors. Plant Mol. Biol. 18:33-45.

Sivasankar, S., Sheldrick, B., and Rothstein, S. J. 2000. Expression of allene oxide synthase determines defense gene activation in tomato. Plant Physiol. 122:1335-1342.

Song, W. C., and Brash, A. R. 1991. Purification of an allene oxide synthase and identification of the enzyme as a cytochrome P-450. Science 253:781-784.

Song, W. C., Funk, C. D., and Brash, A. R. 1993. Molecular cloning of an allene oxide synthase: A cytochrome P450 specialized for the metabolism of fatty acid hydroxides. Proc. Natl. Acad. Sci. U.S.A. 90:8519-8523.

Song, F., Ge, X., Zheng, Z., Wu, W., and Wu, Y. 1994. Effect of two octadecadienoic acid on rice resistance to blast at seedling stage. Chin. J. Rice Sci. 8:162-168.

Stintzi, A., and Browse, J. 2000. The Arabidopsis male-sterile mutant, opr3, lacks the 12-oxophytodienoic acid reductase required for jasmonate synthesis. Proc. Natl. Acad. Sci. U.S.A. 97:10625-10630.

Tamogami, S., Rakwal, R., and Kodama, O. 1997. Phytoalexin production elicited by exogenously applied jasmonic acid in rice leaves (Oryza sativa L.) is under the control of cytokinins and ascorbic acid. FEBS (Fed. Eur. Biochem. Soc.) Lett. 412:61-64.

Thomma, B. P. H. J., Eggermont, K., Penninckx, I. A. M. A., Mauch-Mani, B., Vogelsang, R., Cammue, B. P. A., and Broekaert, W. F. 1998. Separate jasmonate-dependent and salicylate-dependent defense-response 
pathways in Arabidopsis are essential for resistance to distinct microbial pathogens. Proc. Natl. Acad. Sci. U.S.A. 95:15107-11.

Turner, J. G., Ellis, C., and Devoto, A. 2002. The jasmonate signal pathway. Plant Cell 14: S153-S164.

Vijayan, P., Shockey, J., Levesque, C. A., Cook, R. J., and Browse, J. 1998. A role for jasmonate in pathogen defense of Arabidopsis. Proc. Natl. Acad. Sci. U.S.A. 95:7209-7214.

von Malek, B., van der Graaff, E., Schneitz, K., and Keller, B. 2002. The Arabidopsis male-sterile mutant dde2-2 is defective in the ALLENE OXIDE SYNTHASE gene encoding one of the key enzymes of the jasmonic acid biosynthesis pathway. Planta 216:187-92.

Wang, C., Avdiushko, S., and Hildebrand, D. F. 1999. Overexpression of a cytoplasm-localized allene oxide synthase promotes the wound-induced accumulation of jasmonic acid in transgenic tobacco. Plant Mol. Biol. 40:783-93.

Weber, H. 2002. Fatty acid-derived signals in plants. Trends Plant Sci. $7: 217-24$.

Weber, H., Vick, B. A., and Farmer, E. E. 1997. Dinor-oxo-phytodienoic: A new hexadecanoid signal in the jasmonate family. Proc. Natl. Acad.
Sci. U.S.A. 94:10473-10478

Xie, D. X., Feys, B. F., James, S., Nieto-Rostro, M., and Turner, J. G. 1998. COI1: an Arabidopsis gene required for jasmonate-regulated defense and fertility. Science 280:1091-1094.

Xiong, L., Lee, M. W., Qi, M., and Yang, Y. 2001. Identification of defense-related rice genes by suppression subtractive hybridization and differential screening. Mol. Plant-Microbe Interact. 14:685-692.

Xiong, L., and Yang, Y. 2003. Disease resistance and abiotic stress tolerance in rice are inversely modulated by an abscisic acid-inducible mitogen-activated protein kinase. Plant Cell 15:745-759.

Xu, Y., Zhu, Q., Panbangred, W., Shirasu, K., and Lamb, C. 1996. Regulation, expression and function of a new basic chitinase gene in rice (Oryza sativa L.). Plant Mol. Biol. 30:387-401.

Yang, Y., Qi, M., and Mei, C. 2004. Endogenous salicylic acid protects rice plants from oxidative damage caused by aging as well as biotic and abiotic stress. Plant J. 40:909-919.

Ziegler, J., Keinänen, M., and Baldwin, I. T. 2001. Herbivore-induced allene oxide synthase transcripts and jasmonic acid in Nicotiana attenuata. Phytochemistry 58:729-738. 